\title{
Engineering Design Competency: Perceived Barriers to Effective Engineering Design Education
}

\author{
David S. Strong ${ }^{1}$ and Warren Stiver ${ }^{2}$ \\ ${ }^{1}$ Professor and NSERC Chair in Design Engineering, Faculty of Applied Science, Queen's \\ University, Kingston, Ontario, Canada K7L 3N6 strongd@post.queensu.ca \\ ${ }^{2}$ Professor and NSERC Chair in Environmental Design Engineering, School of Engineering, \\ University of Guelph, Guelph, Ontario, Canada N1G 2W1 wstiver@uoguelph.ca
}

\begin{abstract}
The NSERC Chairs in Design Engineering have developed a white paper on Engineering Design Competency. The Engineering Design Competency document was created to stimulate activity in engineering schools and provide a recommended knowledge and skills guideline for engineering educators. However, engineering schools and individual faculty face a number of barriers in their efforts to excel in engineering design education. To make progress, these barriers must be recognized and understood.

This paper will provide a brief review and discussion of five leading barriers to the advancement of engineering design education. The barriers covered are: tenure and promotion policies and procedures, hiring practices, academic structure, funding, and facilities. These barriers are mutually supportive which compounds the challenge.

The paper and presentation will also provide some examples of best practices in overcoming these barriers. The goal of these examples is to provide evidence that none of these barriers are absolute, that all can be overcome, and that some engineering schools are succeeding.
\end{abstract}

\section{Introduction}

"The essence of engineering is design" [1]. Engineering education in North America has typically not reflected this reality for many years. The practice of engineering as seen by practitioners and by faculty are out of sync with one another and it is the practicing engineer who sees engineering "correctly" [2].

Numerous papers have discussed this divergence. Engineering education was largely practice-oriented from its inception through to the middle of the 20th century [3]. It was during and after
WWII that engineering education shifted its focus to encompass more fundamental tools and approaches, spurred by the writings of Dr. V. Bush [4] and the creation of the National Science Foundation. While this shift has lead to an explosion of knowledge, it has also had the unfortunate consequence of disconnecting engineering education from practice and becoming increasingly focused on engineering science [5].

There has been a growing awareness of the issues facing engineering education. As far back as 1955, the Grinter Report [6] presented the need to ensure that curricula contain "....integrated study of engineering design, analysis and engineering systems..."; “...continuing, concentrated effort to strengthen and integrate work in the humanistic and social sciences..."; "...an insistence upon the development of a high level of performance in the oral, written and graphical communication of ideas..."; and, "...the encouragement of experiments in all areas of engineering education." More recent work has confirmed and extended this view to include the need for more multidisciplinary education [3]. One must ask why these needs have not been met for nearly 50 years.

"Our engineering schools are turning out great scientists but mediocre engineers. Mediocre won't make it in the world-wide competition marketplace." [7]. Staying the course will not respond to the increasing criticism from students, industry, the public and the government [8]. According to the Canadian Academy of Engineering, "narrow specialization is not considered to be an appropriate response to expansion in technology". Rather, "engineering graduates should be broadly educated", and undergraduate curriculum "should emphasize problem solving and design" [1].

Brown identifies that design engineers, or, in his words, "technical innovators" are unusual and in great demand [9]. They effectively work in teams, understand the marketplace and economics, and, have 
traditional engineering skills. Developing technical innovators is the mandate of engineering education. Our graduates do not leave with this skill even though they enter first year engineering as a talented group. Clearly, the engineering education system must change.

The need for change is evident. A number of coordinated efforts in support of enhanced design/build and professional skills have been initiated, such as Conceive-Design-Implement-Operate (CDIO) [10], Transferable Integrated Design Engineering Education (TIDEE) [11], Gateway Engineering Education Coalition [12], and the Natural Sciences and Engineering Research Council of Canada (NSERC) Chairs in Design Engineering/Environmental Design Engineering (CDE/CEDE) program [13]. The authors of this paper are chairholders in the NSERC $\mathrm{CDE} / \mathrm{CEDE}$ program. This chair group is working individually and collectively in Canadian Engineering institutions to enhance engineering design training, increase faculty and student collaboration with industry, generate innovative products, processes, and systems, and promote engineering design and the value of design engineering within academe, to industry, and to the public at large.

Another active initiative in support of engineering design in Canada is the Canadian Design Engineering Network (CDEN) [14]. Established with funding from NSERC in 2000, this network was originally established in order to encourage the development and sharing of design engineering educational modules. $\mathrm{CDEN}$ has since evolved into a network with interests that go beyond educational modules, with both steering committee and membership exploring broader interests in support of engineering design education, collaboration, and innovation.

Notwithstanding the many design initiatives that now exist, it is perceived that progress in improving engineering design education, in many cases, is proceeding slowly and with much resistance as a result of a number of "barriers" that commonly exist in many North American engineering education institutions. This paper will review these perceived barriers to effective engineering design education. It is anticipated that the more clearly the barriers are seen and articulated, the more readily they can be overcome. Some examples of best practices in relation to overcoming the identified barriers are also provided.

\section{Barriers}

Barriers to superior design engineering education come in many forms. Fortunately, not all barriers exist at all institutions. It is highly unlikely that any one institution is free of barriers, and similarly unlikely that any one institution has only a single barrier. Barriers appear to be interdependent and dynamic. For the purposes of this paper, the barriers are separated into five areas for convenience of communication alone. The five areas are: tenure, promotion, and rewards; hiring; silos and structures; funding; and facilities.

\section{Tenure, Promotion and Rewards}

Tenure, promotion and reward structures within each institution reflect (or should) the values and priorities of that institution. It is widely recognized that within many institutions and within many engineering programs, the policies have tended towards research and towards archival publications. In the US, the adoption of only the first two of ten recommendations from the Grinter Report has been credited for this research and engineering science emphasis [15].

The "system" has ceased to value interactions with industry [16] or engineering design. No reference is made to design activities or design products in the faculty evaluation documents of 27 US Mechanical Engineering schools [17]. Helms and coworkers criticize academic evaluation systems for ignoring the importance of teamwork which is essential in engineering design [18].

Faculty at all levels are reluctant to add industrial involvement to their already considerable workload and to place possible restrictions on academic freedoms, such as the freedom to publish results [16]. Industry funding, industry design and industry reviews are seen as having less value in the academic engineering world, even though the majority of Bachelor's level engineering graduates pursue industry based engineering careers. This is true even in Mechanical Engineering schools where 100\% of their faculty consider themselves design oriented [18].

Policy revisions by University Presidents, Deans of Engineering or External Funding Agencies will not immediately solve the problem. McPherson and Schapiro indicate that promotion and tenure policies are not effective behaviour modification tools [19]. The essence of academic freedom fundamentally provides individual faculty substantial authority over teaching and research decisions. The academic culture will only shift slowly as individual values do not change overnight.

However, without policy revisions it is unlikely that considerable progress can be made. In the context of retention and success for female faculty, the feeling of satisfaction associated with being valued and recognized by colleagues is important [20]. The same may well be true for design engineering faculty. 
If design engineering is to flourish, design engineers must be valued at all levels. Establishing a critical mass of competent design faculty, along with a capacity and mandate to mentor junior faculty in the field of design engineering, would be one way of demonstrating such value.

New faculty must see design engineering and design engineering education as a viable and valued career path. Currently, the time and effort involved in successful design education is not suited to faculty who have not dedicated themselves to an education priority [15]. The Canadian Academy of Engineering states “...it is well known that published evidence of research accomplishment has historically been the most important consideration in most past decisions on professorial tenure and promotion". The "broadening" of engineering programs may be accepted by many young engineering professors, but "they must be assured that their efforts in promoting the broad design-based process will enhance their career progress" [1].

A key challenge, within any revision to faculty evaluation procedures, is determining how to evaluate design activities and design education. Kundu and Raghunathan indicate that we lack a standard method to evaluate high-quality design education [21]. It is a mistake to avoid design in our faculty evaluation structure just because it is tougher to articulate and to evaluate [8]. "The evaluation processes must measure and give balanced weight to performance and accomplishment in teaching and mentoring as well as in research, engineering design and creative professional practice" [1].

\section{Hiring}

The prominence of hiring faculty without experience in engineering practice does not lend itself to progressive design education. The doctoral graduates from leading engineering schools have focused on research publications and are sought after by academic departments. The reward system encourages them to follow the same path, with the result being that several generations of faculty members “... have never left the campus and they neither understand nor appreciate the role of the technical innovator in society" [9]. The result is that teaching faculty are out of sync with practicing engineering [2]. Faculty can often convey a "god's eye view" of their courses while engineering practitioners recognize that no one individual has a "god's eye view" [2].

Germany's strength in engineering design and engineering design education is partially attributed to the aspect that most professors have considerable industrial experience [22]. Referring to Germany and the Netherlands, Reddaway suggests that faculty have time to teach some of the practice of engineering as well as the fundamentals of engineering science [23]. Furthermore, "there are no status problems and there is a strong contact between industry and technical universities".

Open ended design problems are an essential element of an effective design education [15]. However, open ended problems can be a challenge for faculty lacking non-academic experience [21].

In Canada, MacLean's magazine's "Ranking Canadian Universities" has attracted attention and grown in influence on many campuses [24]. In faculty terms, measurement focuses on the percentage of $\mathrm{PhD}$ 's and funding from the major research granting councils. Non-academic experience in engineering practice and Professional Engineering status is not addressed. In some engineering schools fewer than $50 \%$ of engineering faculty are licensed Professional Engineers.

Denton indicated that in the survey of twelve UK institutions very few faculty had any expertise in team-based design [25]. Development of studentbased, multidisciplinary teams was generally led by faculty with team experience and was not supported by their colleagues who lacked this experience. Successful use of multidisciplinary teams often relied on external expertise or support and encouragement from industrial contacts. Gorman and coworkers reinforced the importance of team skills, stating that, to be successful, team training is needed for faculty [26].

Engineering schools are atypical in their proportion of full-time faculty, for a professional program. Other professions (medicine, law, dentistry) with clinical or practice elements have a much greater role for practicing individuals as part-time faculty [19].

A Canadian Academy of Engineering task force, composed of distinguished professional engineers including current and past Deans of Engineering, Emeritus professors, and senior managers from industry, recommend in their Evolution of Engineering Education in Canada report, that "...a doctoral degree...is not necessarily adequate to provide understanding of the broader aspects of professional engineering practice or to provide the range of skills which are increasingly required for effective education for students. Recruitment of professors after some industrial experience is strongly preferred" [1].

There has been some progress in this area in Canadian engineering institutions. For example, at Queen's University in Kingston, two faculty appointments within the last 3 years were made to non$\mathrm{PhD}$. candidates with extensive, non-academic engineering practice. One is David Strong, Professor 
and NSERC Chair in Design Engineering (and a coauthor of this paper), and the other is Richard Holt, Professor and Industrial Research Chair in Nuclear Materials. Another example is Francois Charron, Professor and NSERC Chair in Design Engineering at the University of Sherbrooke, who also has significant industry experience but not a Ph.D.

The University of Manitoba has significantly increased the involvement of experienced engineering practitioners in engineering education through the employment of "Engineers in residence (EIR)". With a total of 8 EIR's working "part time" (ranging from 20 to $80 \%$ of full time hours), experienced engineers are contributing significantly to design engineering education in Manitoba. It is worth noting that the funding for the EIR's is currently provided through the University's NSERC Chair in Design Engineering, of which Dr. Ron Britton is the chairholder.

\section{Silos \& Structure}

Petroski provides some of the early history on the modularization of engineering [27]. It started in the 1800's when Civil Engineering became distinct from Military Engineering with the formation of the Institute of Civil Engineers in 1818. The Institution of Mechanical Engineers formed in 1847 to meet the needs of new engineers serving railroad expansion.

This early separation of engineering disciplines may have served society well decades ago but many believe that it does not continue to serve design engineering well. "The last half or more of the 20th century, however, has found that the world of practical applications is increasingly cross-disciplinary, and even more rapidly becoming interdisciplinary. The integration across fields in the world of practical applications is often delayed until the engineer has moved into a job rather than being part of his or her university education. Universities, to meet their obligations to students and to society, need to move toward true interdisciplinarity." [28]

In a survey of twelve UK institutions, the modularization of degrees tended to limit cooperation and make sustaining multidisciplinary projects difficult [25]. King argues that the fragmentation of engineering disciplines stifles engineering design creativity through "the narrower perspective afforded by a high degree of specialism" [29].

The need for true interdisciplinarity is driven by increased local and global competitiveness, both because industry is rewarded for getting to market first (first-mover advantage) and because markets are no longer defined geographically. To meet this need, product realization has become a more concurrent and less linear process in most companies, requiring a broad variety of skills on the part of the design team. In addition, the greatest rate of innovation and employment is now in small to medium-sized enterprises. These organizations require employees to have considerable familiarity with all aspects of design. Compartmentalization is no longer an option.

"The engineer must be able to work across many different disciplines and fields. Tomorrow's engineers will need to use abstract and experiential learning, to work independently and in teams, and to meld engineering science and engineering practice." [30]. Students must experience authentic design scenarios that typically require participation across disciplines [15].

It is the interfaces between disciplines that are the most difficult to represent and predict [2]. It is at these interfaces where engineering judgement and experience become most essential. "Incidentally, the most successful engineers in the future will be hyphenated, that is, cross-trained in two or more areas, for example, biomechanical, nanomaterials, or automotive ergonomics." [28]

Engineering programs at Canadian universities are structured by broad engineering disciplines and, at times, by sub-disciplines. The Canadian Council of Professional Engineers (CCPE) identifies approximately 76 different names for actively accredited engineering programs in Canada [31]. Even by grouping these into similar fields, there are still 13 different disciplines. A large number of programs, most of which are highly specialized, simply do not fit easily into any category [32].

Nearly all 36 Canadian engineering schools are departmentalized. This leads to segregation of faculty and students within discipline boundaries. As a result, academic teams and projects rarely engage students from multiple engineering disciplines or students from outside engineering.

Canada's Innovation Strategy points to the "need to encourage cross-training and a multidisciplinary approach, in order to build capacity among MBAs and engineers for the commercialization of these new technologies" [33]. This statement is referring to environmental and green energy; however, it could equally apply to any innovative technology.

Compartmentalization is also a problem at the course level. Students often fail to see the relevance of some of the material taught in a given course and will not see the connection between courses unless their attention is explicitly drawn to it. Courses are often taught as discrete islands of material [2].

There are exceptions to the heavily compartmentalized structure. Harvey Mudd College, widely recognized as a leader in design education, offer an unspecialized engineering major. The 
University of Guelph offers its four engineering programs in a single administrative unit with a substantial common core including a common design sequence.

\section{Funding}

In Canada, the foundation funding program for academic research is the NSERC Discovery Grant system. Many view having a Discovery Grant as an important indicator of research legitimacy for faculty and critically important for new faculty. For decades, the priority for this funding program has been engineering science.

NSERC, to its credit, is committed to a peer review system. Thus, committee decisions reflect the views, values, and experiences of the committees which are most often dominated by successful engineering science researchers. One NSERC Chair in Design Engineering has stated that they explicitly avoid the "design" domain in their own Discovery Grant based on a perception of success. Confirming this concern, one recent reviewer of a Discovery Grant proposal recommended not funding a proposal in which they state "the proposal is of interest to a "field" of engineering staff and management. There is potential for very significant investment decisions to be influenced by such work. ... this is a project related to a "field" of engineering - an essential part of engineering practice, but not one rich in technical problems to be solved." (Note: the specifics of the engineering field have been removed) An interpretation of the reviewer is that research is ONLY about new understanding style discovery, and advancements essential to engineering practice are not worthy of funding.

Faculty with non-academic experience have a lower success rate when applying to the Discovery Grant program [34]. This lower success rate may reflect that engineering practice contributions are harder to assess, that they are less likely to lead to archival journal publications, that these faculty's proposals are potentially more aligned with the development part of the R\&D spectrum and finally that the current selection committees do not value the development part of the spectrum as heavily as they should.

NSERC has been shifting all of its program literature to be more inclusive of design. However, the "entry" program for faculty is the Discovery Grant Program, and the limiting factor will be the values of the selection committees.

A further NSERC initiative is the CDE/CEDE Program with the mandate to advance design engineering education and capabilities in Canadian
Engineering schools [13]. NSERC is also the key supporter of the Canadian Design Engineering Network [14].

In addition to federal support from NSERC, the province of Ontario, through the Ontario Centres of Excellence (OCE), is encouraging R\&D relationships between universities and the marketplace [35]. OCE requires participation of a non-academic partner as one means to ensure that the research and development work respects the ultimate challenge of implementation in society.

\section{Facilities}

There is a clear need to create facilities specific to the pedagogy of project-based design engineering education [15]. These facilities include design studios and associated shops. Dym argues that the investment in these facilities is modest in relation to the cost of lost human engineering talent.

The CDIO initiative [36] introduced by MIT and 3 European Universities, and the Integrated Learning initiative at Queen's [37] both consider purpose-built workspace to be a necessary integral part of effective engineering education, particularly with respect to design and "professional skills". Goldberg would extend the vision for the facilities to support consulting and/or to act as entrepreneurial incubators [8]. However, with few exceptions, most North American engineering schools either do not have such facilities, or do not have them in sufficient quantity to support the full student body.

Design studios are the mainstay of most architectural design education [38]. They readily permit one-on-one meetings, class discussions, design reviews, and the setting for an instructor to be a coach rather than a lecturer. Thompson outlines both facilities and pedagogy for a design studio learning format at the University of Western Ontario [39].

However, active design facilities such as "studios" are only part of the workspace requirement for effective design education. The process of design also typically involves team based discussion, fabrication of prototypes, and their implementation and testing. Hence, ideal workspaces for engineering design education should combine effective and "active" teaching accommodations for classes, as well as workspaces to support creative thinking, facilitate team meetings, offer state of the art design workstations (hardware and software), provide student friendly machine shops and rapid prototyping equipment, supply fabrication and storage space, and offer facilities for implementation and testing of student designs. One recently opened facility that 
combines all of these elements is the Integrated Learning Centre at Queen's University [37].

\section{Change and Summary Remarks}

How much of a barrier to progress in engineering education is change itself? To some extent, human nature tends to resist change, particularly when there is a comfort level with the status quo. Higher education as whole changes slowly - 30 leading innovations in higher education required on average 26 years for the median institution to adopt [40].

Resistance to change is manifested and displayed in many ways. "Denial of the problem is a conspicuous sign of resistance" [41]. In order to endorse change, one must first accept that change is needed. "Resistance to change is viewed as being reinforced by the fundamental myth of engineering education that asserts the supremacy of basic research over all other engineering academic activities....Change is viewed with suspicion, if at all, and many consider it largely unnecessary..." [8]. Given extensive studies and new initiatives in engineering education that suggest change is needed, why hasn't adoption of such change been more widely accepted and acted upon?

Another cause of resistance to change can be an individual's unfamiliarity with the new direction. It isn't surprising that faculty who have little or no industry experience would not feel confident in the area of professional practice and practical engineering design skills. Hence, after first recognizing this deficiency exists, it is reasonable to assume that "some faculty members need further education" [41].

As indicated in the description of previous barriers, there is little incentive for change towards more effective design engineering education when the priorities are elsewhere. It has been suggested that there is a conflict of interest with respect to teaching design when teaching engineering science is often easier, is closer to research interests, and can be done without "time consuming" contacts with industry. "Forward looking and wise engineering faculty leadership could resolve this ...but change is resisted by those who profit from the status quo" [41].

Academic freedom permits individual faculty, particularly those with tenure, to change ahead of the system. However, academic freedom also permits conservatism for those who are resistant to change.

The barriers that prevail are all mutually supportive and are interdependent. Progress will rely on:

- overcoming all of the barriers in tandem.
- developing a critical mass of engineering academics that are committed to design education.

- developing a critical mass of engineering academics that are practicing design in their research.

- the non-academic community taking an active role in engineering education.

The future lies in achieving a balance within our engineering schools. This balance recognizes the need for engineering design faculty in addition to engineering science faculty. Both faculty streams must be valued, rewarded, and supported. This also recognizes that faculty with considerable engineering practice experience are an important asset to any engineering school. State of the art facilities are essential for both engineering design and engineering science to flourish. Engineering is a profession that serves the needs of society; it is therefore critical that engineering schools - students, staff and faculty - must be integrated broadly with other disciplines as well as the non-academic world.

\section{Acknowledgements}

Funding for this work has been provided by NSERC of Canada's Chairs in Design Engineering (CDE) and Environmental Design Engineering (CEDE) programs. The authors would like to thank their CDE/CEDE colleagues for their support and their initial work in relation to barriers.

\section{References}

[1] Canadian Academy of Engineering, 1999, Evolution of Engineering Education in Canada.

[2] Bucciarelli L.L., 2003, Designing and learning: a disjunction in contexts, Design Studies, 24:295-311.

[3] Crawley E., 2002, Creating the CDIO Syllabus, a Universal Template for Engineering Education, Proc. Frontiers in Education Conference, ppF3F.8-F3F.12.

[4] Bush V., 1945, Science - The Endless Frontier, United States Government Printing Office, Washington, D.C.

[5] Crawley, E., 2001, The CDIO Syllabus: A Statement of Goals for Undergraduate Engineering Education, Tech. Rep., MIT CDIO, Dept. of Aeronautics and Astronautics, Cambridge, MA.

[6] Grinter, L.E., 1955, Report of the Committee on Evaluation of Engineering Education, J. Engineering Education, 46(1):25-60.

[7] Nicolai, L.M., 1998, Viewpoint: An Industry View of Engineering Design Education, Int. J. Engineering Education, 14: 7-13.

[8] Goldberg, D.E., 1996, Change in Engineering Education: One Myth, Two Scenarios, and Three Foci, J. Engineering Education, 85(2):107-116. 
[9] Brown W.S., 1985, Educating Technical Innovators for US Industry, European J. Engineering Education, 10:103-107.

[10] CDIO, 2005, www.cdio.org/index.html

[11] TIDEE, 2005, www.tidee.cea.wsu.edu/

[12] Gateway, 2005, www.gatewaycoalition.org/

[13] NSERC Chairs in Design Engineering Program, www.nserc.gc.ca/professors e.asp?nav $=$ profnav $\& \mathrm{lbi}=\mathrm{c}$ $\underline{3}$

[14] NSERC Canadian Design Engineering Network Program, www.nserc.gc.ca/news/2000/p000524-2.htm

[15] Dym C.L., Agogino A.M., Eris O., Frey D.D. Leifer L.J., 2005, Engineering Design Thinking, Teaching, and Learning, J. Engineering Education, 94:103-120.

[16] EEIC 1997, Best Practices Summary Report, Workshop on Building Effective Industry/Academe Partnerships for Engineering Education Innovation, Fred Beaufait, chair, presented to the Engineering Education Innovators Conference, April 7,8 1997, Arlington VA.

[17] Todd R.H., Magleby S.P., 2004, Evaluation and Rewards for Faculty involved in Engineering Design Education, Int. J. Engineering Education, 20(3):333340.

[18] Helms M.M., Williams A.B., Nixon J.C., 2001, TQM Principles and their Relevance to Higher Education: The Question of Tenure and Post-tenure Review, Int. J. Educational Management, 15/7:322-331.

[19] McPherson M.S., Schapiro M.O., 1999, Tenure Issues in Higher Education, J. Economic Perspectives, 13(1):85-98.

[20] August L., Waltman J., 2004, Culture, Climate and Contribution: Career Satisfaction among Female Faculty, Research in Higher Education, 45(2): 177192.

[21] Kundu A.K., Raghunathan S., 2000, A proposition in design education with a potential in commercial venture in small aircraft manufacture, Aircraft Design, $3: 261-273$

[22] Wallace K.M., Blessing L.T.M., 2000, Observations on Some German Contributions to Engineering Design in Memory of Professor Wolfgang Beitz, Research in Engineering Design, 12:2-7.

[23] Reddaway, J.L., 1980, A Survey of Engineering Design Education in North America, Europe, and Japan, as cited in Ferguson, E.S. (1992) Engineering and the Mind's Eye, chapter 6:165.

[24] Maclean's Magazine, www.macleans.ca

[25] Denton, H.G., 1997, Multidisciplinary Team-Based Project Work: Planning Factors, Design Studies, 18:155-170.

[26] Gorman M.E., Johnson V.S., Ben-Arieh D., Bhattacharyya S., Eberhart S., Glower J., Hoffman K., Kanda A., Kuh A., Lim T.W., Lyrintzis A., Mavris D., Schmeckpeper E., Varghese P., Wang Y., 2001 Transforming the Engineering Curriculum: Lessons Learned from a Summer at Boeing, J. Engineering Education, 90(1):143-149.

[27] Petroski, H., 2002, Remembering the Future, ASEE Prism, 11(7):17.
[28] Coates J.F., 2000, Innovation in the Future of Engineering Design, Technological Forecasting and Social Change, 64:121-132.

[29] King T., 1995, Millwrights to Mechatronics: The Merits of Multi-disciplinary Engineering, Mechatronics, 5:95-115.

[30] Bordogna J., 1997, Making Connections: The Role of Engineers and Engineering Education, The Bridge Archives, 27(1):11-16.

[31] CCPE, 2004, Accredited Engineering Programs, www.ccpe.ca.

[32] CCPE, 2003, Canadian Engineers for Tomorrow. Trends in Engineering Enrollment and Degrees Awarded, www.ccpe.ca

[33] Government of Canada, 2002, National Summit on Innovation and Learning: Summary, www.innovationstrategy.gc.ca, Ottawa.

[34] NSERC Update, 2005 Discovery Grant Results, www.appsci.queensu.ca/research/publications/presentat ions/NSERC update May2005.pdf

[35] Ontario Centres of Excellence, 2005, www.oceontario.org

[36] Berggren, K-F, Brodeur, D., Crawley, E.F., Ingemarsson, I., Litant, W., Malmqvist, J., Östlund, S., 2003, CDIO: An International Initiative for Reforming Engineering Education, World Transactions on Engineering and Technology Education, 2(1):49-52.

[37] Strong, D.S., McCowan, J.D., 2005, Effective Workspace for Engineering Education: The Integrated Learning Centre at Queen's University in Kingston, in Proc. $2^{\text {nd }}$ Annual CDEN Design Conference, Kananaskis, Alberta, July.

[38] Sachs A., 1999, 'Stuckness' in the design studio, Design Studies, 20:195-209.

[39] Thompson, Brian E., 2002, Studio Pedagogy for Engineering Design; Int. J. Engineering Education, 18(1):39-49.

[40] Getz M., Siegfried J.J., Anderson K.H., 1997, Adoption of innovations in higher education, Quarterly Review of Economics and Finance, 37(Fall):605-631.

[41] Jones, J.B., 1991, Design at the Frontiers of Engineering Education, Frontiers in Education, Session 22P1: 107-111. 